\title{
Changes of dynamic properties of mobile scenes at various steps of their manufacturing
}

\author{
Michat Liss ${ }^{1, *}$, and Valeriy Martynyuk ${ }^{2}$ \\ ${ }^{1}$ Bydgoszcz University of Science and Technology, Faculty of Mechanical Engineering, Al. prof. S. \\ Kaliskiego 7 85-796 Bydgoszcz, Poland \\ ${ }^{2}$ Khmelnytsky National University, 29016, 11, Instytutska Street, Khmelnitsky, Ukraine
}

\begin{abstract}
Mobile stage construction is a huge challenge for designers due to a very wide range of variable factors influencing it, such as wind or temperature, the value of which in this case depends on the geographical location. An inherent element of the impact of these factors are the accompanying different, both constant and variable loads. Detailed identification of these loads is as important as the analysis of the dynamic properties of the structure. The more so as the analyzed structure appears in two configurations, first as a semitrailer, and then as a stage.
\end{abstract}

\section{Introduction}

Mobile stages are mainly steel or steel-aluminum truss structures commonly used in the entertainment industry. They are usually the central part of any major event. Therefore, they should be characterized by a high safety factor, which is indirectly influenced not only by the technical condition of the structure, but also by its dynamic properties [1,2]. The vast majority of engineering calculations for such structures is limited only to determining the resistance to static loads, which are especially justified in the case of a distributed mobile scene. However, it should be taken into account that mobile scenes also have the ability to move, and thus are exposed to the influence of dynamic loads occurring during motion [1,3]. There are numerous cases of the negative impact of dynamic loads on the technical condition of structures [4], in which this phenomenon is explained in detail. Thus, there is a clear need to determine the dynamic properties of this type of technical objects already at the stage of its production in order to identify the behavior of the entire structure during its normal operation. The obtained information will make it possible to observe changes in the state of the structure, and in effect to assess whether there is a loss of its stiffness or stability. On the other hand, they can be used to develop appropriate rules for the operation of this type of structure, which would boil down to excluding from the sensitive ranges phenomena that could strengthen the resonance areas. In yet another case, the structure is modified on the basis of the estimated dynamic properties. Each of these solutions boils down to the same goal in the form of obtaining the properties of the structure, for which, in the assumed range, there will be no resonance reinforcements of the vibration response to possible dynamic excitations.

\section{Identification of dynamic properties}

\footnotetext{
* Corresponding author: michal.liss@pbs.edu.pl
} 
The identification of the dynamic state of machines, along with the model description and research methods of these models, is anchored in the process of constructing and operating modern machines and technical devices [5,6,7]. The field that develops this topic is called modal analysis. It is now a well-proven method of testing the dynamic properties of mechanical structures and more. The result of the process of this analysis is a modal model of the structure, which can be the basis for solving various engineering problems such as [813]:

$>$ analysis of the behavior of a mechanical structure under the influence of various types of excitations,

$>$ optimization of the dynamic properties of the structure (fig. 1),

$>$ minimization of acoustic energy radiation,

$>$ diagnosing the condition of machines,

$>$ fatigue strength analysis, etc.

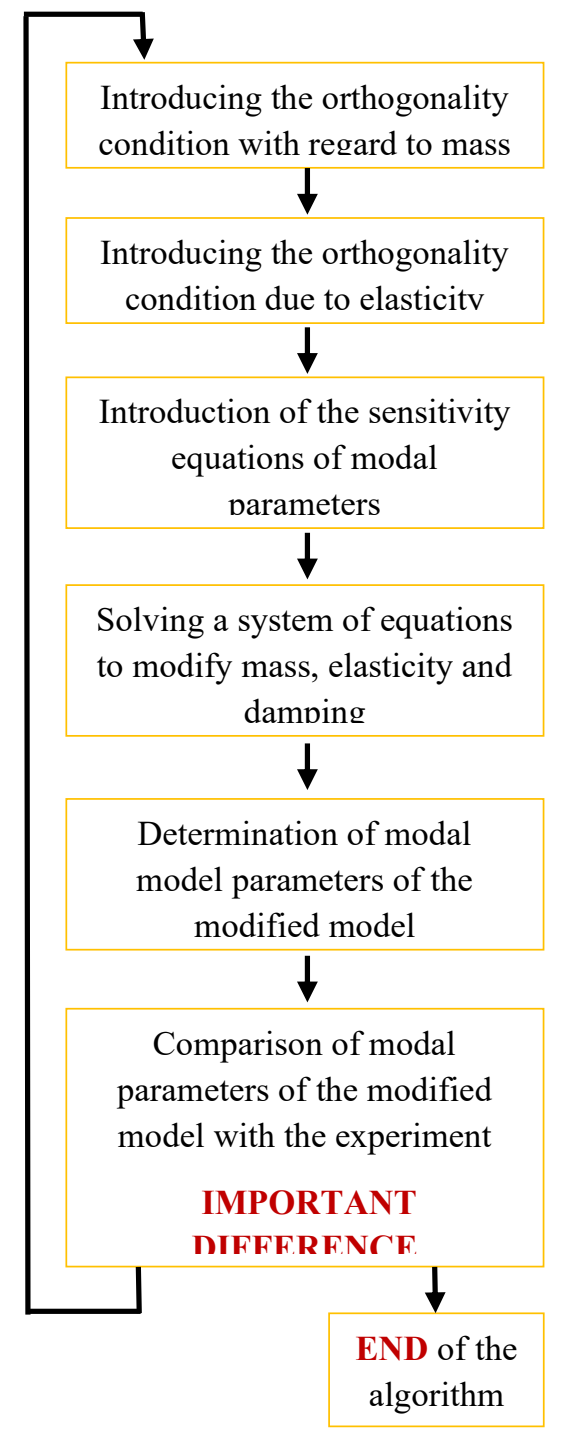

Fig.1. Modification of the model based on the results of modal research $[11,13]$. 
This method is based on algorithms that enable testing the sensitivity of the models to changes in their modal parameters. Appropriate analysis of these sensitivities provides the basis for determining the place in the structure where changes of properties should be made in order to obtain the maximum shift of the natural frequency or to reduce the modal displacement in the selected area of the structure for the selected natural frequency $[10,11]$. The methods of modifying dynamic properties are divided into three groups [11]:

$>$ local modification,

$>$ attaching components,

$>$ structural decomposition.

The first of the three groups includes a set of methods that add or subtract masses, dampers, or elastic elements from a modified system at one or more points of the structure in order to shift the natural frequency or reduce the modal displacement. The second group includes methods which consist in adding an additional system or multiple systems with a known modal model to the modified structure. This model can be used to simulate the dynamic behavior of an object under any extortion. The third group, on the other hand, includes methods that involve subtracting certain subsystems from the modified structure, which has an impact on the dynamic properties of the final form of the structure.

The influence of the dynamic properties of the structure on the obtained response values resulting from the acting dynamic load is shown schematically in Figure 2.

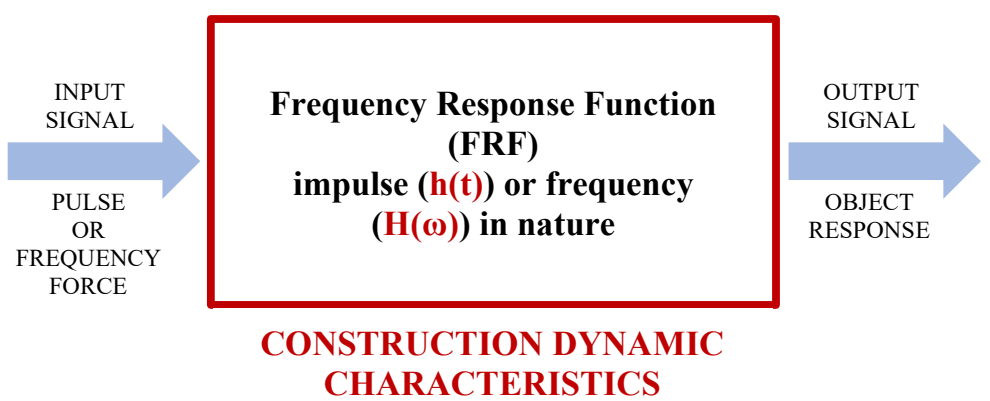

Fig.2. The method of determining the dynamic properties of a mechanical structure [6].

The diagram shown in Figure 2 shows that based on the measured input signals and the responses of the mechanical structure, either impulse $(h(t))$ or frequency $(H(\omega))$ time characteristics are determined, thus creating a dynamic model. Determining one of these two functions allows to obtain a full description of the dynamic behavior of the tested structure.

\section{Object and measuring system}

One of the most important elements of the construction of the mobile stage is the chassis (Fig. 3), to which the rest of the stage is attached in the form of a landing, roof, roof columns and other systems supporting the use of the stage. The dynamic properties of the chassis oscillate in the low frequency range, up to a maximum of $1000 \mathrm{~Hz}$. The tests of the dynamic properties of the mechanical structure were carried out under in situ conditions. 


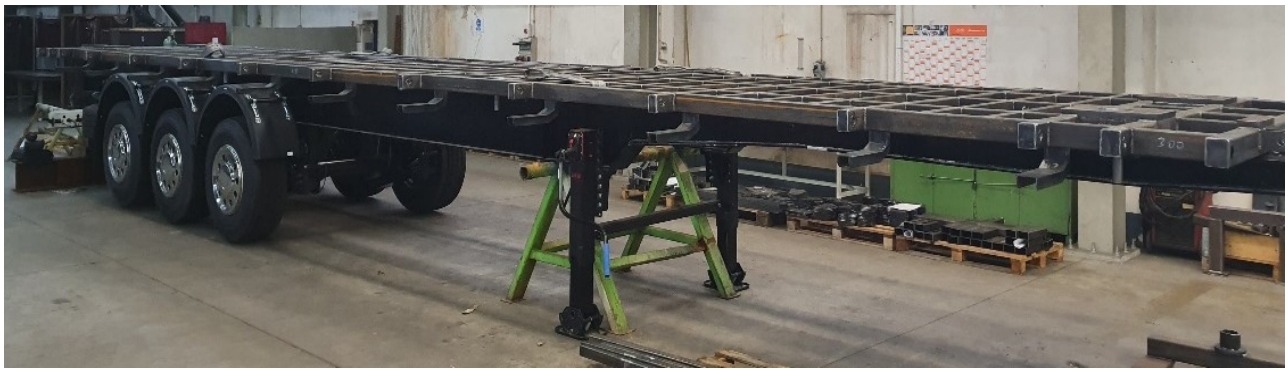

Fig.3. The chassis of the mobile stage.

First, modal tests were carried out only on the chassis of the mobile stage in order to determine its characteristic dynamic properties. In the further part of the research, they constitute the starting point for subsequent modal models. Thanks to this, it is possible to accurately determine the scale of changes in the dynamic properties of the structure at each subsequent stage of its manufacturing steps.

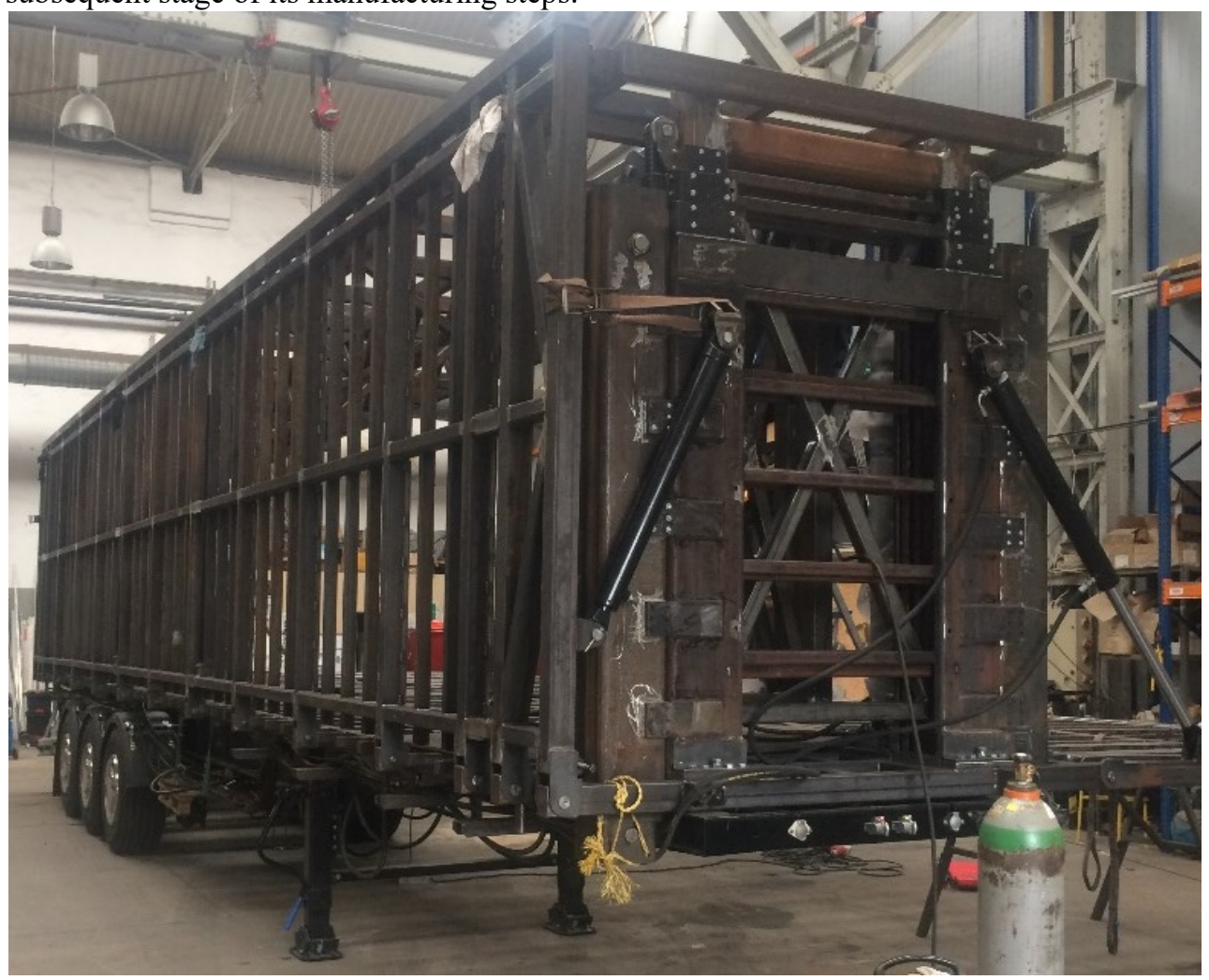

Fig.4. The rest of the structure is attached to the chassis.

The state of the recently tested mechanical structure is shown in Figure 4. The article presents the results of research on dynamic properties from three production stages of the mobile stage:

a) TEST A - chassis of the mobile stage with complete brake, suspension and drive systems,

b) TEST B - mobile stage chassis with an attached stage platform, 
c) TEST C - chassis of the mobile stage with fixed columns, roof structure and hydraulic actuators to control the assembly process and dismantling the stage.

The measuring system consists of a recording device (LMS Scadas Recorder - SCR05), a three-axis vibration acceleration sensor (T356A16) and a modal hammer (086C03) used to introduce a force to the mechanical system in the form of a Dirac pulse. On the construction of the mobile stage, 24 measurement points were established, in which the response of the system to a given excitation in three axes: X, Y, Z, in the range up to $1024 \mathrm{~Hz}$, was recorded. The measuring system is shown in Figure 5.

The distribution of individual measurement points is shown in Figure 6. Figure 6 is also an approximate geometric model of the mobile stage chassis, which was used to visualize the selected results.

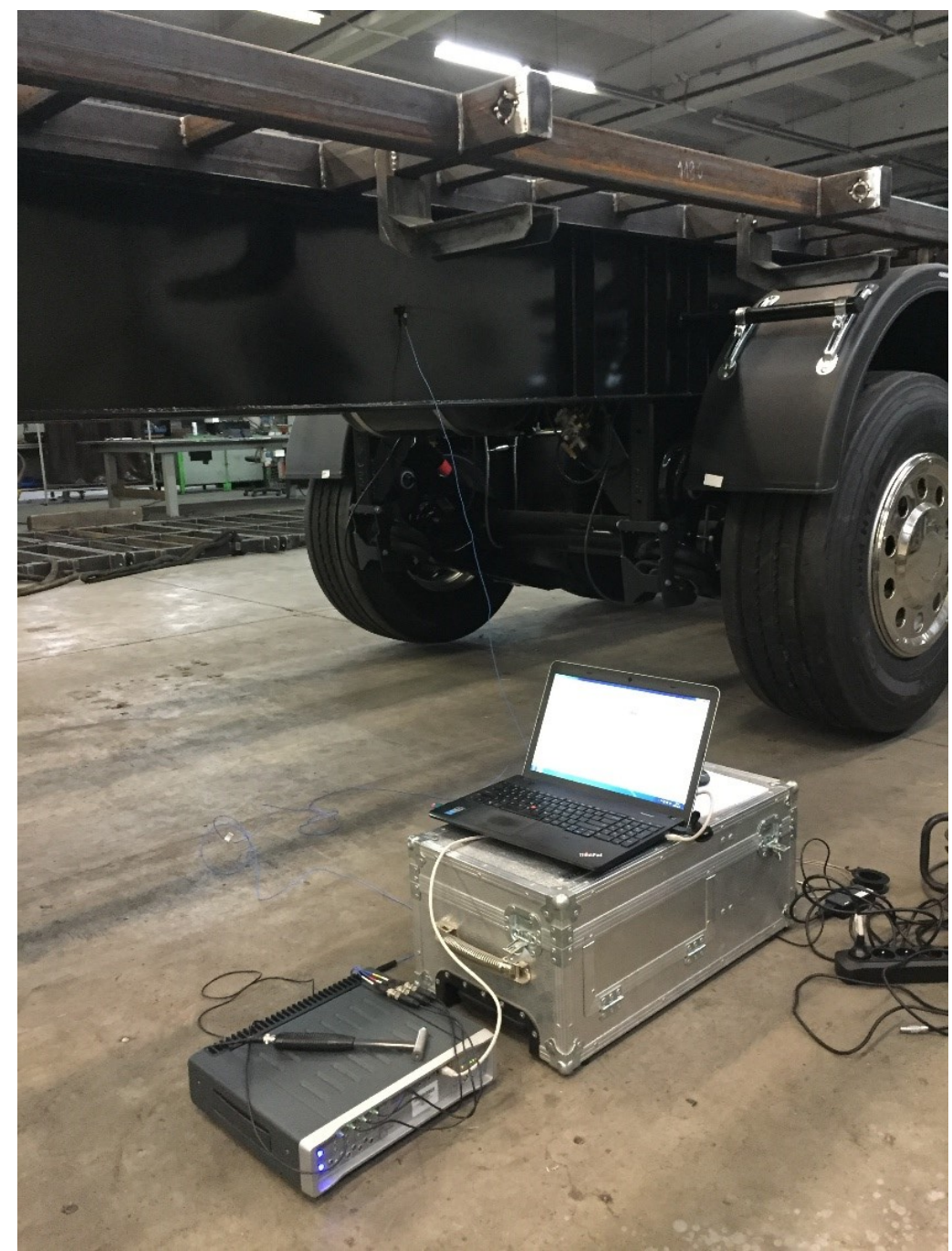

Fig.5. The measuring system used.

It should be noted that the measuring points $C: 10$ to $C: 15$ are located on the running gear side of the chassis. The measurement was carried out using the SIMO method using a tool based on the so-called roving hummer. 


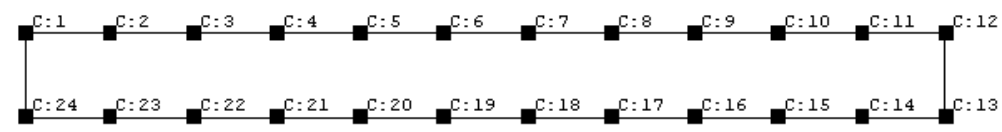

Fig.6. Arrangement of individual measurement points.

\section{Results}

The key element enabling the proper determination of the dynamic properties of the tested object is the form of a stabilization diagram and the order of the model at which it is possible to determine the key modal parameters. The verification process of the determined vibration parameters is very tedious and is not the subject of this publication.

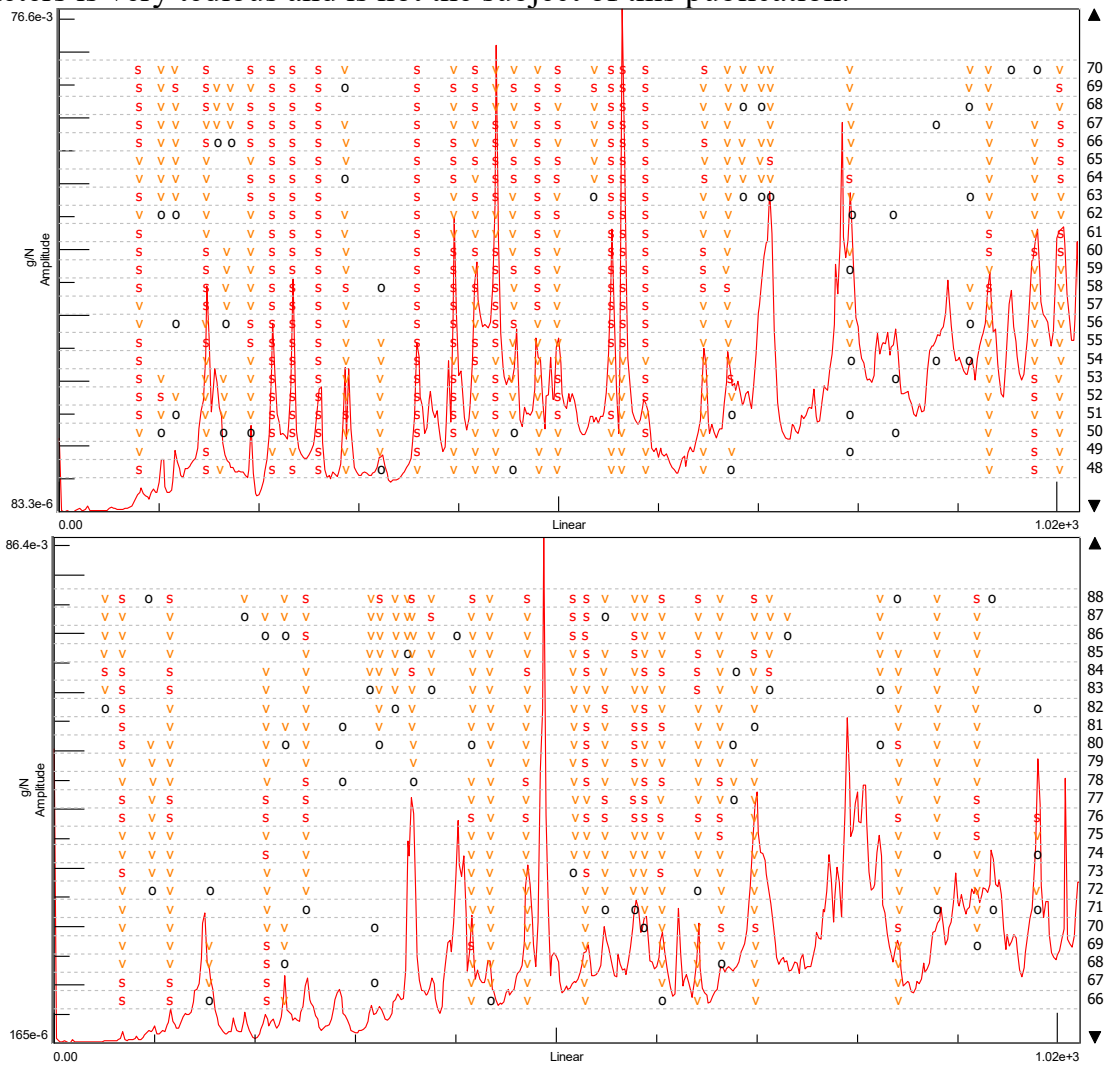




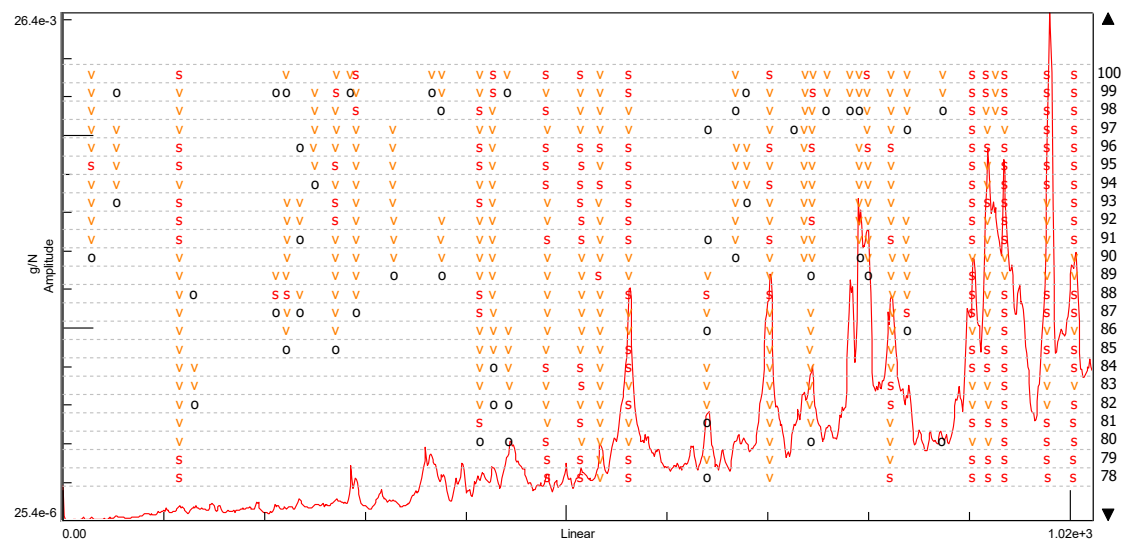

Fig.7. Stabilization diagrams for each of the three manufacturing steps of mobile stage.

The analysis of the results begins with the comparison of stabilization diagrams that describe the dynamic state of the object in the selected production stage. Each of the stabilization diagrams combines in some way the spectral transition functions of each measurement point using a special tool called the SUM indicator. When analyzing the spectral transition function separately at each individual measurement point, we would notice at some point that we are determining similar modal parameters. This is an ideal situation to use the SUM indicator tool saving a lot of time. The SUM indicator, in a sense, compares all the spectral transition functions from twenty-four measurement points, focusing mainly on the places of peak occurrence and their vibration amplitude. If there is a peak in a similar location on the frequency axis, the SUM indicator averages, enhancing or weakening its vibration amplitude. The same is happening with the remaining peaks appearing in the designated FRF plots.

The stabilization diagrams presented in Figure 7 clearly illustrate the changes in the dynamic properties of the tested object and the scale in which they occurred at each of the three analyzed stages of the production of the mobile scene. Especially in the third stage, the significant increase in the weight of the structure contributed to a dramatic change in its dynamic state. Table 1 shows the basic structural vibrations of the chassis of the mobile stage at each step of its production.

Table 1. Structural vibrations of the chassis of the mobile stage at various steps of its production.

\begin{tabular}{|c|c|c|c|}
\hline L.p. & Natural frequency [Hz] & Modal damping factor [\%] & Model row \\
\hline \multicolumn{5}{|c|}{ Test A } \\
\hline 1 & 80,088 & 0,63 & 51 \\
\hline 2 & 359,221 & 0,29 & 51 \\
\hline \multicolumn{5}{|c|}{ Test B } \\
\hline 1 & 115,793 & 0,42 & 66 \\
\hline 2 & 357,425 & 0,17 & 68 \\
\hline \multicolumn{5}{|c|}{ Test C } \\
\hline 1 & 115,624 & 0,71 & 61 \\
\hline 2 & 414,093 & 0,10 & 76 \\
\hline 3 & 561,808 & 0,26 & 72 \\
\hline 4 & 822,170 & 0,13 & 67 \\
\hline
\end{tabular}

Based on the results presented in Table 1, it is stated that the first two modes of natural vibrations are one of the most important structural vibrations of the chassis of the mobile stage. The first form of free vibrations in test A occurred at a frequency of approx. $80 \mathrm{~Hz}$, 
while the changes introduced in test B resulted in its shift to a frequency of approx. $115 \mathrm{~Hz}$, with slight changes in the form of vibrations. The comparison of the first form of vibrations from tests A and B is shown in Figure 8.

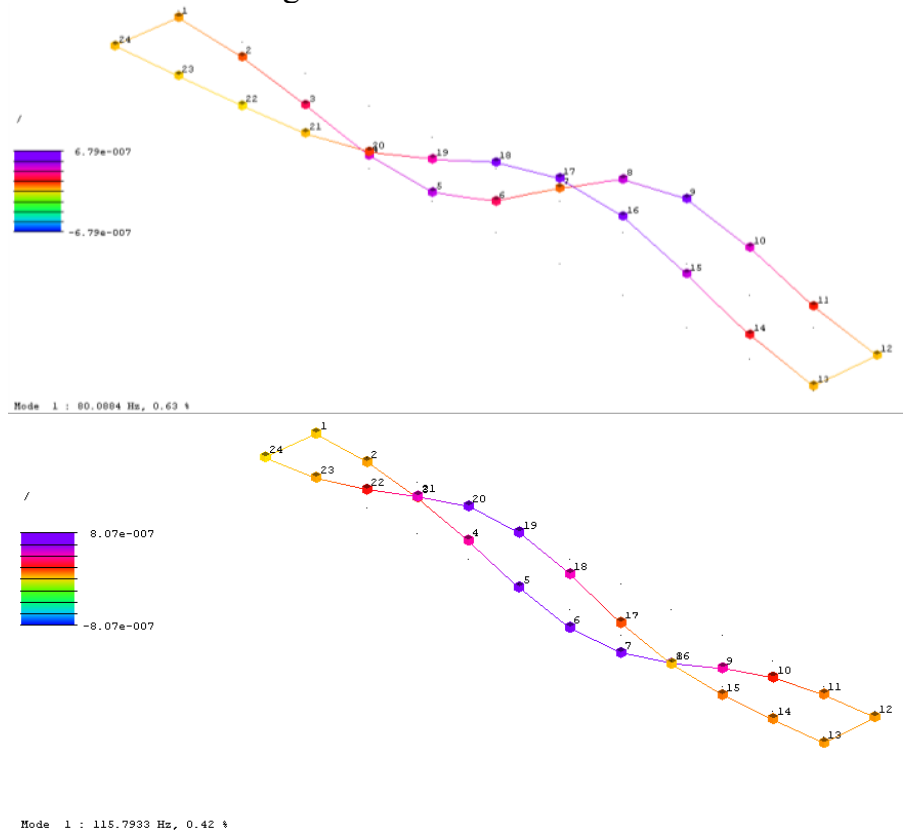

Fig.8. Comparison of the first form of vibration from tests A and B.

The form of free vibrations in both cases retained the same bending-torsional character. Only the amplitude of vibrations has changed, focusing in the central part of the chassis of the mobile stage. On the other hand, the changes introduced to the structure in the third stage of the production of the mobile stage caused that the first mode of free vibration slightly shifted in the frequency axis. The determined first mode of free vibrations in test $\mathrm{C}$ clearly shows the dynamic changes in the structure that took place. Figure 9 shows the first mode of free vibration in test $\mathrm{C}$.
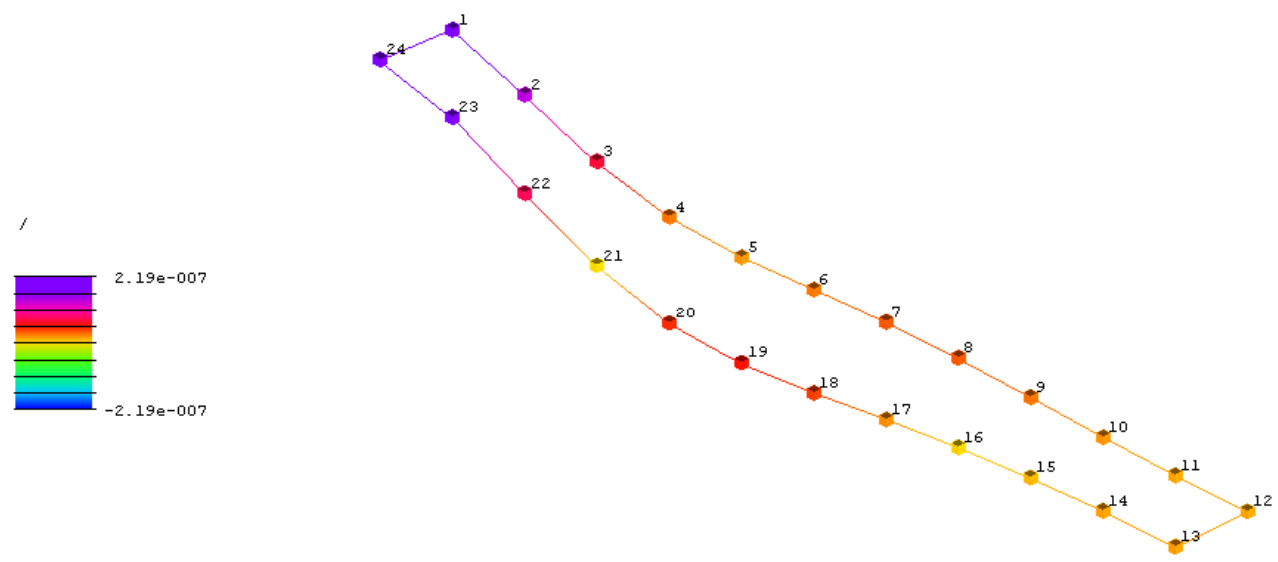

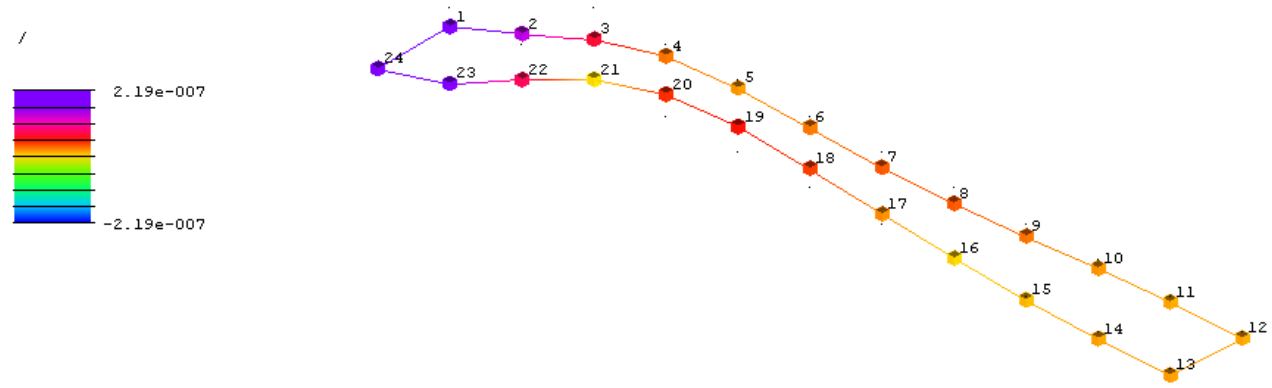

Mode $1: 115.6240 \mathrm{~Hz}, 0.71 \%$

Fig.9. Extreme deflections of the first mode of free vibrations from test $\mathrm{C}$.

The form of free vibrations shown in Fig. 9 is mainly bending in nature, which positively affects the chassis structure, for which torsional vibrations are particularly dangerous. Certainly, this form of vibration would be even more beneficial if the tested chassis was attached to a tractor unit. The high vibration amplitude of the left part of the landing gear is attributed to the unsupported part of the structure. The profile of the chassis frame is also much smaller at this point, up to the point of its enlargement, which falls on points 4 and 21 . The chassis support is also located at the height of this measuring point.

The situation is similar in the case of the second mode of free vibrations, the form of which both in test A and B looks very similar. The difference in the level of vibrations by about $2 \mathrm{~Hz}$ is visible graphically in the form of a shift of the vibration amplitude towards the front part of the mobile stage chassis. The second form of free vibrations of the chassis, similarly to the previous cases, changed significantly only in test $\mathrm{C}$. The change in the structure of the mobile stage causes the second form of free vibrations in test $\mathrm{C}$ to occur in out-of-phase. Additionally, in test $\mathrm{C}$, two completely new natural frequencies appeared.

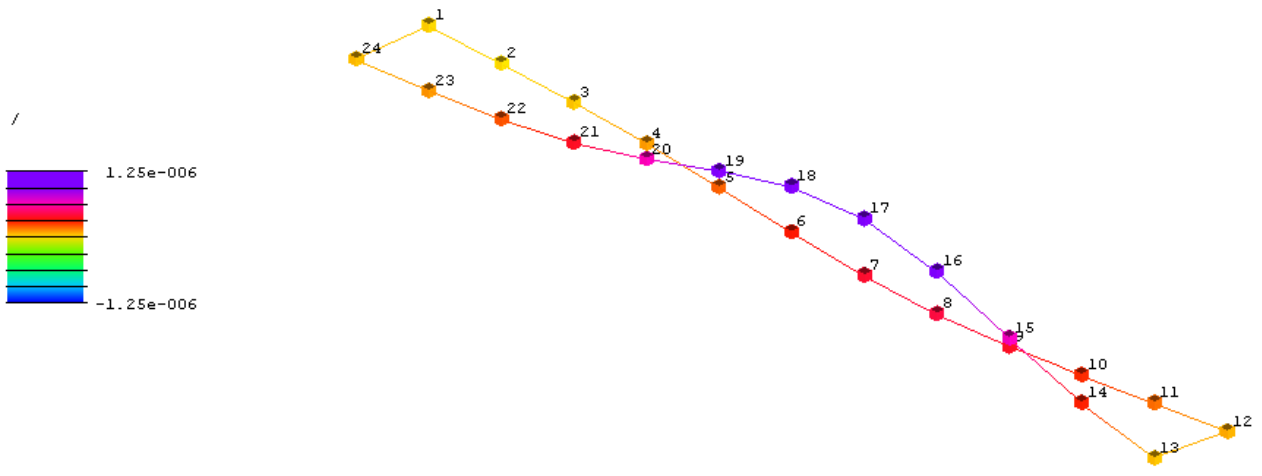

Mode $z: 359.2205 \mathrm{~Hz}, 0.29 *$ 


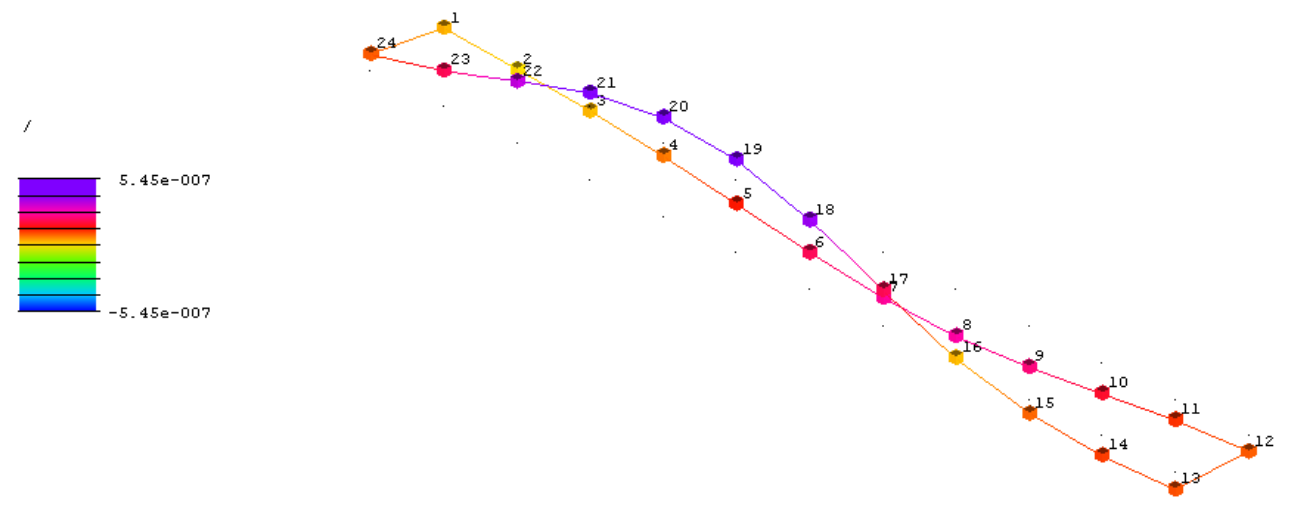

Mode $2: 357.4246 \mathrm{~Hz}, 0.17 *$

Fig.10. Comparison of the second form of vibration from tests A and B.

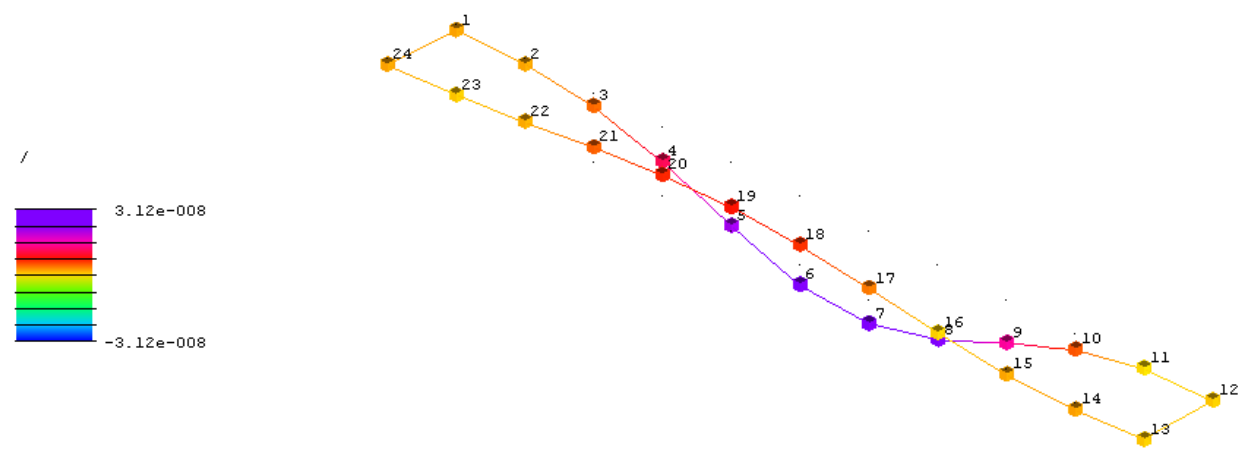

Mode $2: 414.0929 \mathrm{~Hz}, 0.10 *$

Fig.11. The second form of free vibration from test $C$.

\section{Conclusion}

The rapid development of the entertainment industry contributes to the emergence of more and more sophisticated mobile stage designs, and recently it has been an absolute phenomenon to create scenes with very large usable areas of the stage platform. Producers of mobile scenes in this case struggle with many limitations, both domestic and international, sometimes forgetting how the changes that have occurred translate into the dynamic properties of the scenes. The presented results clearly show how simple it is to interfere with the dynamic state of the structure and how important it is to monitor changes of this type. Otherwise, the lack of control of the dynamic state of the structure may contribute to the occurrence of situations in which the vibration responses to the given excitation will intensify. The effect of this phenomenon will be a high risk of the initial stages of damage development, not only of a fatigue nature.

This paper has been achieved under the research project "Hybrid multimedia mobile scenes are a chance for decisive innovation" No. POIR.04.01.04-00-0045/17-00. 


\section{References}

1. E. Radziszewska - Zielina, E. Kania, G. Śladowski, Problems of the Selection of Construction Technology for Structures in the Centres of Urban Agglomerations, Archives of Civil Engineering, 64(1), pp. 55-71 (2018)

2. J. Szer, Safety of Buildings and Construction Disasters, Archives of Civil Engineering, Vol. LXVI, Issue 1, pp. 281-295 (2020)

3. W. Siłka, Teoria ruchu samochodu, WNT, Warszawa (2002)

4. M. Drzazga, Uwzględnienie oddziaływań dynamicznych na konstrukcję trybun, Przegląd budowlany, nr 12, pp. 40-45 (2013)

5. J. Bednarz, T. Uhl, A. Piłat, Diagnostyka maszyn wirnikowych oparta na modelu, Diagnostyka, nr 3 (43), pp. 25-35 (2007)

6. I. Sordyl, F. Sordyl, Identyfikacja własności dynamicznych konstrukcji wsporczej części prasowej maszyny papierniczej w warunkach eksploatacyjnych, Diagnostyka, nr 2 (42), pp. 83-92 (2007)

7. T. Uhl, Zastosowane analizy modalnej w diagnostyce maszyn, Diagnostyka, nr 23, pp. 87-92 (2000)

8. T. Kalaczynski, V. Martynyuk, J. Boiko, S. Matyukh, S. Petrashchuk, Exploitation aspects of diagnostic hydraulic and pneumatic systems of Multimedia Hybrid Mobile Stages, 19th International conference diagnostics of machines and vehicles hybrid multimedia mobile stage, Matec Web of Conference, Vol. 332, pp. 1-10 (2021)

9. B. Żółtowski, M. Żółtowski, M. Łukasiewicz, Statistical research space of measures of vibration energy in machines, Engineering Mechanics 2018, Vol. 24, pp. 965-968 (2018)

10. W. Heylen, S. Lammens, P. Sas, Modal Analysis Theory and Testing, Katholieke Universiteit Leuven, Heverlee (2007)

11. T. Uhl, Komputerowo wspomagana identyfikacja modeli konstrukcji mechanicznych, Wydawnictwo Naukowo - Techniczne, Warszawa (1997)

12. T. Uhl, W. Lisowski, Eksploatacyjna analiza modalna, Wydawnictwo Katedry Dynamiki Maszyn i Robotyki, Kraków (1999)

13. T. Uhl, W. Lisowski, Praktyczne problemy analizy modalnej konstrukcji, Wydawnictwo AGO, Kraków (1996) 